since the slump year of 1924 , despite the fact that no change in the plankton was noted. J. H. Orton reports on the oyster beds of the Fal Estuary. On the banks the beds are in poor condition, largely owing to dirty culch. Overgrowth of sponges and Lithothamnion is a troublesome factor. In the river, conditions are better and it is suggested that clean culch from this region should be spread over the banks every June to assist in recovery. Crepidula fornicata has not appeared in the area. The experimental rearing of oyster larvæ over five seasons at Port Erin Biological Station provides the material for a lengthy report by J. M. Bruce, Margery Knight and Mary Parke. This important piece of work deals chiefly with the food supply of the larvæ, and the cultivation of algal zooids acceptable to them. It is in some respects supplementary to $H$. A. Cole's work on the biological and physical conditions affecting oyster culture at Conway. Six flagellate organisms were eventually chosen and cultivated and were fed to the veliger larvæ under stabilized biophysical conditions, either separately or mixed. The most successful were those labelled $H$ and $I$, greenish yellow or golden brown flagellates $3-6 \mu$ in diameter. Using them as food, more than 90 per cent of the larvæ settled as spat. The adaptation of the experimental results to commercial practice is the next problem to be solved.

\title{
LARGE-SCREEN TELEVISION PROJECTION
}

$\mathrm{T}$ $\mathrm{HE}$ application of television has so far been restricted by the difficulty of obtaining received pictures comparable in size and brightness with those produced by the cinematograph, whether used in the home or in places of public entertainment. Consideration of the matter leads to the conclusion that this objective is unlikely to be achieved until it is practicable to apply the principles of optical projection of the pictures, using a standard form of light source of a magnitude suitable for the size of picture required.

In an article published in the February-March issue of Electronics and Television and Short-Wave World, Dr. A. H. Rosenthal describes a new electronic device by means of which such projection may be realized, without the disadvantages accompanying the use of an intermediate film on which the picture is first recorded photographically and then projected in the usual manner. The principle of the device is based upon the discovery by $\mathrm{E}$. Goldstein in 1894, that certain materials, normally transparent to visible light, become coloured, that is, more or less opaque, when they are subjected to bombardment by cathode rays. Examples of such materials are the halides of the alkaline earth group, and potassium chloride has been used in the application of this discovery to television reception.

In the instrument developed by Dr. Rosenthal, which he terms a 'Skiatron', the screen of the cathoderay receiving tube is replaced by a plate of potassium chloride crystals, mounted between two lighttransparent electrodes. As the plate is scanned in the normal manner by the beam of electrons, an opaque deposit is produced, the density of which is everywhere proportional to the instantaneous intensity of the beam. The screen thus carries during each frame period a complete quasi-stationary picture, which may be projected optically in a manner similar to that employed with a cinematograph film. The opaque deposit is removed by the application of a steady electric field between the electrodes placed on either side of the crystal, the spoed of obliteration increasing with the field strength and also with increase of temperature of the crystal.

In the instrument under development, the magnitudes of these quantities are chosen so that the 'picture' deposits are removed in the interval between successive scannings. Owing to the fact that the picture being projected is quasi-stationary, as com. pared with the continuously varying one produced on the fluorescent screen of the usual cathode-ray tube, the picture repetition frequency used in the 'Skiatron' can be reduced to a value just sufficient to avoid flicker. If this advantage is substantiated in practice, the effective band of radio frequencies required by the television transmitter will be reduced.

In the article referred to, Dr. Rosenthal illustrates an arrangement of using three of these special tubes for reproduction of coloured pictures. Each cathoderay tube with its special crystal screen and a suitable light filter operates at one of each of the three primary colours used, and the illumination is projected directly through the three screens in succession to obtain the coloured resultant picture.

\section{PROBLEMS OF EVACUATION}

$\mathrm{T}$ HE report of an inquiry, which has been pursued by the Department of Social Science of the University of Liverpool, financed by a grant from the CharitiesF und of theLiverpool Council of Social Service, into problems of evacuation has now been published under the title "Our Wartime Guests-Opportunity or Menace" (Liverpool : University of Liverpool Press. London : Hodder and Stoughton, Ltd., $6 d$. net). It emphasizes the importance of a determined effort to profit as much as possible from the mistakes of what may prove to be only the first of a series of evacuation schemes. Like the interim report, which dealt with the evacuated areas, the present report is based on house-to-house visiting, this time in the reception areas. The results of these 412 interviews lead to the reassuring conclusion that the evacuation scheme, despite its voluntary basis, has not entirely broken down. The majority of the hosts behaved splendidly and succeeded in making the children entrusted to them happy. Many of the parents co-operated to the best of their abilities.

That the scheme was not a complete success was due to faulty organization in the billeting of dirty, verminous and enuretic children; the removal of children from their billets by parents on the impulse of the moment; the unwillingness of some hosts to 
accept the heavy extra work and surrender of their freedom involved; and the influencing of public opinion against the scheme by those who did not wish to co-operate. Moreover, those who believed the scheme was workable did not express themselves strongly enough, and no central authority was appointed in reception areas to deal with the problems which arose, to give a lead to parents and hosts who were uncertain in their attitude and to undertake active propaganda to. influence public opinion in favour of the scheme. Such a central authority in each district ready to offer advice on all difficult problems, particularly psychological ones of behaviour, could undoubtedly have smoothed out many of the difficulties and led to the children remaining in the safe areas. So far as there have been breakdowns in the scheme, the administrative machinery would appear to be at fault rather than any fundamental weakness in the ties which bind our community together, or absence of public spirit on the part of hosts or parents of evacuated children. If the authorities concerned had used the services of tutors qualified in medical psychology or carried out a short research before the scheme was drawn up, many mistakes would have been avoided.

The report also stresses the possibility of basing action on precise knowledge with the development of social psychology. It directs attention to the need for extended research on enuresis and its treatment, the widespread existence of which was indicated in the inquiry. The scheme also demonstrated that the general standards of cleanliness and hygiene leave much to be desired, and the appreciation of the value of education is much lower in a certain group of the population than might have been supposed. Much could be done to correct this attitude by strengthening the school medical service, and the use of new means of education and propaganda.

In regard to the apportionment of responsibility for individual failures, the inquiry showed that 60 per cent of the parents were to blame for taking their children home without justifiable cause, 30 per cent of the hosts sent the children away because they did not wish to co-operate and only 10 per cent of the children returned because they were ill-behaved or fretting.

\section{LIMITATION OF TRANSFORMER NOISE}

$\mathrm{T}$ RANSFORMERS are particularly suited for outside use in outside distribution of electricity, owing to the facility with which they can be installed and the saving effected, but if they are a nuisance to dwellers in their neighbourhood, something has to be done immediately to suppress their noise. Noise prevention is a matter for co-operative investigation, and this was the reason why the Electrical Research Association (E.R.A.) formed a committee in 1934, composed of gas, electric and water engineers, under the chairmanship of Prof. B. O. Kapp, to consider the best means of eliminating this trouble. Definite contributions have been made to our knowledge by this committee, and by papers and discussions on the subject contributed to the engineering societies. An interesting paper on the limitation of transformer noise was contributed to the Institution of Electrical Engineers on March 28, the authors being B. G. Churcher and A. J. King, of the MetropolitanVickers Electrical Co., Ltd.

Before considering means for reducing noise to allowable proportions, we should be able to determine its value both as regards quantity and quality. In the case of transformers, the latter is not so important as in the case of some kinds of machinery in which the sound varies in pitch. Nevertheless, the annoyance which can be caused by transformer hum is very real.

It is axiomatic that trouble should, if possible, be eliminated at its source. The authors and those who took part in the discussion on their paper showed there is very little to be gained by altering the design of transformers within permissible commercial limits. Dr. Swaffield has recently shown that the main cause of transformer noise is magnetostriction, that is, vibration due to change in length and in the area of the core that occur together, under the influence of the impressed magnetic field. The old idea that tightening core bolts and clamping could effect appreciable improvement has been shown to be wrong. Attempts to limit the effects of magneto-striction by reducing the density of the magnetic flux yield only very slight relief at a great cost.

The Electrical Review of April 5 gives a good illustration of the material values of the study that has been expended on this subject. When the $\mathbf{7 5 , 0 0 0} \mathrm{kva}$. transformers were installed at Fulham Power Station about three and a half years ago, all means were taken to avoid being a cause of offence. The transformers were run at a low flux density and the tanks rested on rubber pads. Each transformer was housed in a brick chamber without openings. This last precaution was probably much the most effective.

Many think that efforts to obtain a silent transformer will probably be fruitless. Attenuation of unavoidable sound offers the most promising field of attack. Hence the authors put forward, as a less costly alternative to bricking-in, where conditions would otherwise make that necessary, a scheme of barriers within a larger tank which would absorb both radial and longitudinal sound waves. Even apart from the dominant consideration of the background level of noise, almost every case has to be considered on its merits. Distance and structure of the surrounding houses are principal factors, but even here resonance sometimes gives rise to curious phenomena.

The first need appears to be to secure a standard attenuation acceptable in ordinary. conditions, and then to provide means to predict with certainty the additional attenuation required to meet the peculiarities of local circumstances. In addition, the establishment of noise-levels regarded as tolerable would be helpful, if only because (since psychology enters into the equation) objection to constituted standards would appear unreasonable. It may be fairly claimed that research on present lines augurs well for an economical solution of the noise problem, without departing from the well-established principles of transformer design. 